\title{
Morphometric and Morphological Study of Mental Foramen in the Malaysian Population: Anatomy and Forensic Implications.
}

\author{
Aspalilah Alias (AA) MMedSC ${ }^{1,2}$, AbdelNasser Ibrahim (ANI) MSc ${ }^{1,3}$, Siti Noorain Abu Bakar (SNAB) BSc ${ }^{1}$, \\ Mohamed Swarhib Shafie (MSS) DMJ ${ }^{1}$, Srijit Das (SD) MS ${ }^{4}$, Faridah Mohd Nor (FMN) PhD ${ }^{1}$ \\ ${ }^{1}$ Forensic Unit, Department of Pathology, Universiti Kebangsaan Malaysia Medical Centre, Jalan Yaakob \\ Latif, Bandar Tun Razak, 56000 Kuala Lumpur, Malaysia. \\ ${ }^{2}$ Faculty of Dentistry, Universiti Sains Islam Malaysia, Tingkat 15, Menara B, Persiaran MPAJ, Jalan Pandan \\ Utama, Pandan Indah, 55100 Kuala Lumpur, Malaysia. \\ ${ }^{3}$ Department of Forensic Medicine and Clinical Toxicology, Faculty of Medicine, Al Azhar University, Cairo, \\ Egypt. \\ ${ }_{4}^{4}$ Department of Anatomy, Universiti Kebangsaan Malaysia Medical Centre, Jalan Yaacob Latif, Bandar Tun \\ Razak, 56000 Kuala Lumpur.
}

\begin{abstract}
Introduction: The mental foramen is present on either side of the body of the mandible bone. This foramen transmits mental vessels and nerves. In forensic anthropology, mental foramen may be important for differentiating sex, estimating age and identifying various races based on morphology. The main aim of the present study was to determine the position, shape and diameter of the mental foramen according to sex, age and race by postmortem computed tomography in the Malaysian population. Materials and Methods: A total of 79 dentulous patients (48 males, 31 females) from 3 age groups (18-30 years, 31- 50 years, 51-74 years) were selected for this study, and ten parameters were observed for each mandible. The parameters were divided into two morphological and eight morphometric parameters. The morphometric parameters were measured by using Osirix MD Software 3D Volume Rendering. Results: Results showed that mandibular body length and height were significantly greater in males than in females by independent $t$-test. $(p<0.05)$. However, the mandibular body height was found to decrease significantly with age in both sexes by one-way Anova. It was observed that the shape of mental foramen was $45.6 \%$ oval and $54.4 \%$ rounded. About $44.3 \%$ of them were in line with the longitudinal axis of the second premolar tooth. Conclusion: It was concluded that mental foramen may be used for identification purposes, particularly for sex, age and race determination.
\end{abstract}

KEYWORDS: anthropology, mandible, sex, age, race.

Introduction

The mental foramen is present in the body of the mandible, and it transmits mental vessels and nerves. In forensic anthropology, analysing the morphological features of the bone is important as it can differentiate between sex, age and race ${ }^{1}$. The mandible is the strongest bone in the human face, and it is preserved much longer compared to other bones. Compared to other parts of mandible, mental foramen is usually selected due to its stability and

Correspondence:

Assoc. Prof. Dr. Faridah Mohd Nor,

Department of Pathology,

Universiti Kebangsaan Malaysia Medical Centre,

Jalan Yaacob Latif, Bandar Tun Razak, Cheras,

56000 Kuala Lumpur, Malaysia

Email add: mnfaridah@gmail.com

Tel. No: (603) 91455368 (603) 91455369

Fax No: (603) 91456676 durability ${ }^{2}$. According to the literature, the mental foramen is located between the apices of the premolars or the second premolar, from which the mental nerve and vessels emerge ${ }^{3}$. However, studies have reported variations in the position of the mental foramen ${ }^{4-14}$.

The direction of the foramen bears much clinical significance, especially with regard to administration local anaesthesia to the mental nerve. The knowledge of position of mental foramen is important in cases of surgery and implant placement ${ }^{15}$. The mental nerve is the terminal branch of the inferior alveolar nerve and it traverses the mental foramen giving sensory innervation to the lower lip, buccal vestibule and gingiva medial to the first mandibular molar ${ }^{4}$.

The mental foramen vary in position with regard to age, and it can be influenced by other demographic 
factors such as sex and ethnicity ${ }^{16}$. Skeletal development in bones, cranial sutures and teeth takes place at specific ages ${ }^{17}$. Estimation of age is important after sex determination in the identification of human remains. Estimation of age becomes more difficult as bone matures ${ }^{18}$.

There are several methods, which have been proposed for identification and these include radiological, histological and chemical analysis ${ }^{18}$. The radiographic method is the simplest and cheapest method of age, sex and race determination when compared to histological and biochemical methods ${ }^{1}$. Panoramic radiograph, periapical radiograph, Magnetic Resonance Imaging (MRI), Cone Beam Computed Tomography (CBCT), Spiral Computed Tomography (SCT) and Multi-Slice Computed Tomography (MSCT) were used in the past to determine the position of mental foramen ${ }^{19}$ 23. In Malaysia so far, the mental foramen has been only studied by using panoramic radiograph ${ }^{24}$. To the best of our knowledge, the present study is the first of its kind to use postmortem computed tomography (PMCT) to determine the position of the mental foramen for identification of sex, age and race in the Malaysian population.

\section{Materials and Methods}

This study was a retrospective study conducted at Hospital Kuala Lumpur. The database was collected from postmortem computed tomography (PMCT) images retrieved from the Department of Forensic Medicine, Hospital Kuala Lumpur. The sample comprised all individuals with documented sex, race and age received by the mortuary for four years duration from January, 2012 till June, 2016. A total of 79 dentulous mandibles were obtained (48 males and 31 females). The subjects were in three age groups, i.e. $18-30$ yrs $(n=26) ; 31-50$ yrs $(n=31)$ and 51-74 yrs ( $n=22)$ and were divided into three ethnic, racial groups i.e. Malays (32), Chinese (20) and Indians (27).

All intact and well formed, adult mandibles were chosen for the study. The pathological, edentulous, deformed or broken mandibles were excluded from the study. The morphology and position of the mental foramen were described accordingly, while morphometric measurements of mental foramen were measured on the right side of each mandible by using Osirix MD software from $3 D$ Volume Rendering. The measurements in centimetres $(\mathrm{cm})$ were rounded off to nearest 2 decimal places. The study was approved by the Medical Ethics Committee, Faculty of Medicine, Universiti Kebangsaan Malaysia Medical Centre (UKM
PPI/ 111/8/JEP-2016-359).

\section{Morphological Parameters}

i) The shape of the right side of mental foramen was described as either round or oval. (Fig. 1)

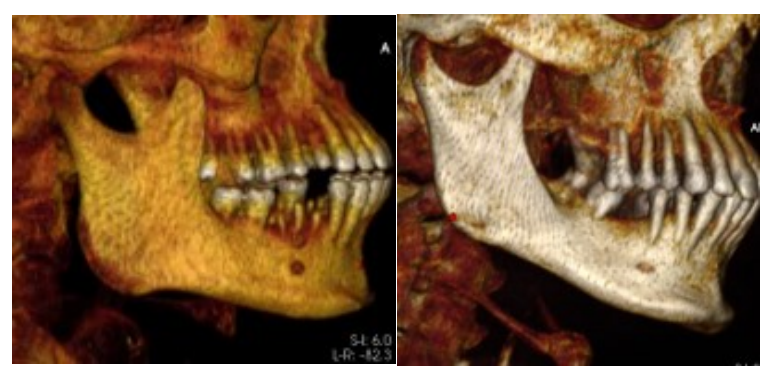

Fig. 1 PMCT of mental foramen on the right side of mandible.

(a- rounded type of mental foramen, $b$ - oval type of mental foramen)

ii) Based on earlier research protocols, the position of mental foramen was classified according to the longitudinal axis of the mandibular teeth as described below [25-26]: (Fig. 2)

a. Position 1 - Foramen lying on a longitudinal axis passing between canine and first premolar.

b. Position 2 - Foramen lying on the longitudinal axis of first premolar.

c. Position 3 - Foramen lying on a longitudinal axis passing between first and second premolars.

d. Position 4 - Foramen lying on the longitudinal axis of second premolar.

e. Position 5 - Foramen lying on a longitudinal axis passing between second premolar and first molar.

f. Position 6 - Foramen lying on the longitudinal axis of the first molar.

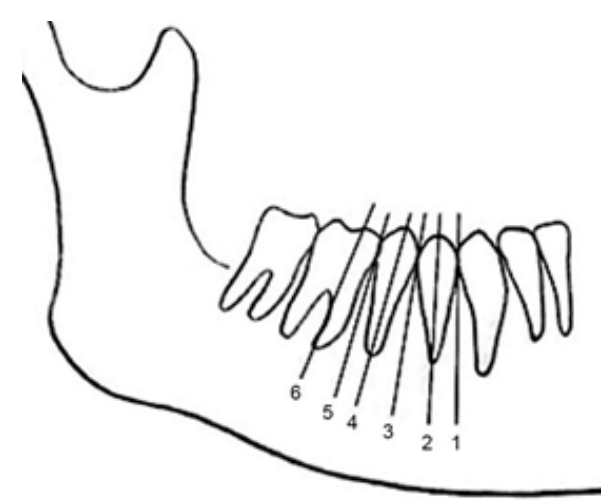

Fig. 2 Schematic representation of the numeric expression of position of mental foramen relative to the teeth. Adapted from [26] 


\section{Morphometric Parameters}

There were eight morphometric parameters as described below [27]. (Fig. 3)

a. AC-Distance from alveolar crest to upper margin of mental foramen.

b. $B D$ - Distance from lower border of mandible to lower margin of mental foramen.

c. $A B$ - Distance from alveolar crest to lower border of mandible.

d. VD - Vertical diameter of foramen, $(A B$ $(A C+B D)$.

e. WY - Distance from symphysis menti to medial margin of mental foramen.

f. $\quad X Z$ - Distance from posterior border of ramus of mandible to lateral margin of mental foramen.

g. WX - Distance from symphysis menti to posterior border of ramus of mandible.

h. $H D$ - Horizontal diameter of foramen, $W X$ $(W Y+X Z)$.

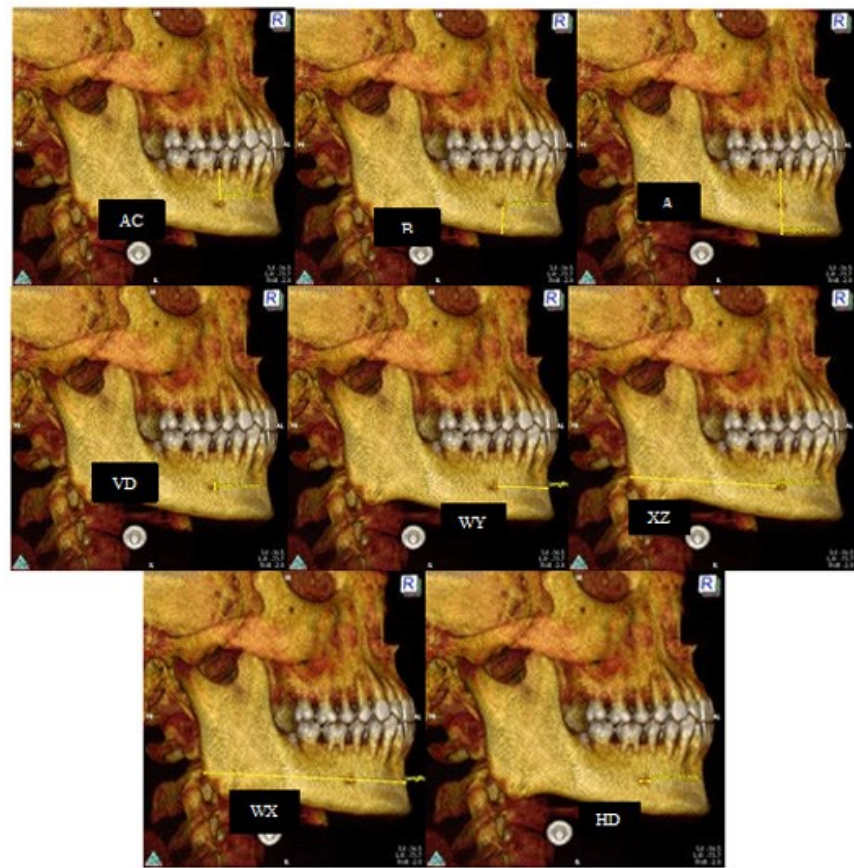

Fig. 3 Measurements of eight morphometric parameters in mental foramen $(A C, B D, A B, V D, W Y, X Z, W X, H D)$ using $3 D$ Volume Rendering.

\section{Statistical analysis}

The independent $t$ - test was used to compare between males and females. One-way ANOVA was used to compare the significant differences between the different age groups. The data were analysed using SPSS version $22^{28}$.

\section{Results}

Results showed that mental foramen was rounded and oval in $54.4 \%$ and $45.6 \%$ of mandibles, respectively. (Fig. 4) The commonest position of mental foramen was in line with the longitudinal axis of second premolar (position 4) (44.3\%), followed by foramen lying on a longitudinal axis passing between second premolar and first molar (position 5) (30.4\%), foramen lying on a longitudinal axis passing between first and second premolars (position 3) (19\%) and foramen lying on the longitudinal axis of the first molar (position 6) (6.3\%). The mental foramen didn't present in position 1 and 2 in any of the mandibles observed. (Table I) In this study, however the commonest shape of mental foramina that were present in all the positions were not analysed.

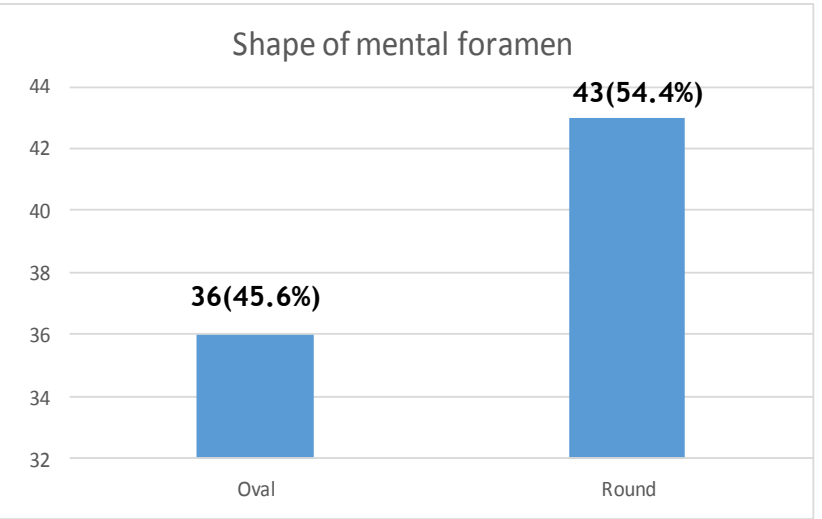

Fig. 4 The bar chart of different shapes of mental foramen in the sample population.

Table I. The position of mental foramen was classified according to the longitudinal axis of the mandibular teeth. (Position I-6)

\begin{tabular}{|c|c|c|c|c|c|c|}
\hline Position & $I$ & 2 & 3 & 4 & 5 & 6 \\
\hline$N(\%)$ & 0 & 0 & $\begin{array}{l}15 \\
(19 \%)\end{array}$ & $\begin{array}{l}35 \\
(44.3 \%)\end{array}$ & $\begin{array}{l}24 \\
(30.4 \%)\end{array}$ & $\begin{array}{l}5 \\
(6.3 \%)\end{array}$ \\
\hline
\end{tabular}

In this study, there were significant differences in $B D, A B$ and $W X$ measurements between males and females with independent t-test. $(p<0.05)$ (Table II) There were significant differences in $A C$ and $A B$ measurements among different age groups by oneway ANOVA. $(p<0.05)$ (Table III) However, there was no significant difference in all the parameters between the three racial groups. (Table IV) 
Table II. The mean and standard error of mean (SEM) of morphometric mental foramen measurements in male and female.

\begin{tabular}{|l|l|l|l|}
\hline Parameters & $\begin{array}{l}\text { Male (Mean } \\
\pm \text { SEM) }\end{array}$ & $\begin{array}{l}\text { Female } \\
\text { Mean } \pm \\
\text { SEM) }\end{array}$ & $\begin{array}{l}\text { Sig. (' } p \text { ' } \\
\text { Value) }\end{array}$ \\
\hline$A C$ & $1.02 \pm 0.03$ & $1.00 \pm 0.02$ & 0.64 \\
\hline$B D$ & $1.05 \pm 0.03$ & $0.93 \pm 0.02$ & $0.01^{* *}$ \\
\hline$A B$ & $2.56 \pm 0.04$ & $2.43 \pm 0.03$ & $0.03^{*}$ \\
\hline$V D$ & $0.48 \pm 0.01$ & $0.49 \pm 0.01$ & 0.77 \\
\hline$W Y$ & $1.65 \pm 0.05$ & $1.69 \pm 0.05$ & 0.61 \\
\hline$X Z$ & $5.74 \pm 0.15$ & $5.54 \pm 50.08$ & 0.31 \\
\hline$W X$ & $8.08 \pm 0.10$ & $7.74 \pm 0.12$ & $0.03^{*}$ \\
\hline$H D$ & $0.55 \pm 0.12$ & $0.50 \pm 40.02$ & 0.08 \\
\hline
\end{tabular}

Table III. The mean and standard error of mean (SEM) of morphometric mental foramen measurements in different age groups.

\begin{tabular}{|c|c|c|c|c|}
\hline \multirow{2}{*}{$\begin{array}{l}\text { Parame- } \\
\text { ters }\end{array}$} & \multicolumn{4}{|c|}{ Age groups } \\
\hline & $\begin{array}{l}18-30 \text { yrs } \\
\text { old } \\
\text { (Mean } \pm \\
\text { SEM) }\end{array}$ & $\begin{array}{l}31-50 \\
\text { yrs old } \\
\text { (Mean } \pm \\
\text { SEM) }\end{array}$ & $\begin{array}{l}51-74 \\
\text { yrs old } \\
\text { (Mean } \pm \\
\text { SEM) }\end{array}$ & $\begin{array}{l}\text { Sig. } \\
\text { (' } p \text { ' } \\
\text { Value) }\end{array}$ \\
\hline$A C$ & $\begin{array}{l}1.13 \pm \\
0.02\end{array}$ & $\begin{array}{l}0.98 \pm \\
0.04\end{array}$ & $\begin{array}{l}0.92 \pm \\
0.03\end{array}$ & $0.01^{* *}$ \\
\hline$B D$ & $\begin{array}{l}0.99 \pm \\
0.04\end{array}$ & $\begin{array}{l}1.00 \pm \\
0.03\end{array}$ & $\begin{array}{l}1.03 \pm \\
0.04\end{array}$ & 0.84 \\
\hline$\overline{A B}$ & $\begin{array}{l}2.62 \pm \\
0.05\end{array}$ & $\begin{array}{l}2.50 \pm \\
0.04\end{array}$ & $\begin{array}{l}2.40 \pm \\
0.04\end{array}$ & $0.01^{* *}$ \\
\hline$V D$ & $\begin{array}{l}0.48 \pm \\
0.02\end{array}$ & $\begin{array}{l}0.51 \pm \\
0.19\end{array}$ & $\begin{array}{l}0.44 \pm \\
0.02\end{array}$ & 0.08 \\
\hline$W Y$ & $\begin{array}{l}1.64 \pm \\
0.06\end{array}$ & $\begin{array}{l}1.71 \pm \\
0.05\end{array}$ & $\begin{array}{l}1.64 \pm \\
0.07\end{array}$ & 0.68 \\
\hline$X Z$ & $\begin{array}{l}5.71 \pm \\
0.11\end{array}$ & $\begin{array}{l}5.62 \pm \\
0.20\end{array}$ & $\begin{array}{l}5.67 \pm \\
0.16\end{array}$ & 0.91 \\
\hline$W X$ & $\begin{array}{l}7.89 \pm \\
0.14\end{array}$ & $\begin{array}{l}8.07 \pm \\
0.10\end{array}$ & $\begin{array}{l}7.85 \pm \\
0.16\end{array}$ & 0.47 \\
\hline$H D$ & $\begin{array}{l}0.53 \pm \\
0.02\end{array}$ & $\begin{array}{l}0.54 \pm \\
0.019\end{array}$ & $\begin{array}{l}0.53 \pm \\
0.02\end{array}$ & 0.93 \\
\hline
\end{tabular}

${ }^{* *} p<0.01$

\section{Discussion}

In humans, the mandible is one of the earliest bones to commence ossification. This bone is unique in its embryological origin as the bone undergoes both endochondral and intramembranous ossification. The coronoid and condylar process of mandible undergoes endochondral ossification, while the body of mandible undergoes intra-membranous ossification. The changes in the morphological and teeth eruption in mandible, aid in age estimation until the third decade of life ${ }^{29}$. Further studies on the mandible are required after the third decade of life as the mandibular changes may be subtle ${ }^{30}$. In forensic, age, sex and race determination play a vital role in the identification of an individual ${ }^{31}$. The bone is considered an important tool for identification of skeletal remains as they can provide an approximation of age, sex and race ${ }^{32}$.

In this study, 79 mental foramina were assessed. The mental foramina were found to be in line with the longitudinal axis of the second premolar in $44.3 \%$ of mandibular observed. This study was compared with several other studies in other populations, i.e. in the Pakistanis ${ }^{33}$, Singaporean Malays and Indians ${ }^{34}$ and Saudi population ${ }^{10}$. On the contrary, in Caucasian populations, the mental foramen was located between the first and second premolars $^{36}$, while in Tanzania, Thai, Chinese, British and Saudi Arabia, the location of the mental foramen varied between populations ${ }^{37}$.

The common positions include between two premolars, along the long axis of the second premolar and between the second premolar and first molar teeth ${ }^{38-42}$. These variations of position in mental foramen may be attributed to different ethnic and racial groups. However, in the present study, there was no difference in all the parameters among three races i.e. Malays, Chinese and Indians. By independent $t$-test, the height and length of the mandibular body showed significant difference between males and females with higher values found in males than females, $(p<0.05)$ and the results were in accordance with the literature ${ }^{43-45}$. (Table II)

Table IV. The mean and standard error of mean (SEM) of morphometric mental foramen measurements in Malay, Chinese and Indian

\begin{tabular}{|c|c|c|c|c|}
\hline \multirow{2}{*}{$\begin{array}{l}\text { Parame- } \\
\text { ters }\end{array}$} & \multicolumn{4}{|c|}{ Racial groups } \\
\hline & $\begin{array}{l}\text { Malay } \\
\text { (Mean } \pm \\
\text { SEM) }\end{array}$ & $\begin{array}{l}\text { Chinese } \\
\text { (Mean } \pm \\
\text { SEM) }\end{array}$ & $\begin{array}{l}\text { Indian } \\
\text { (Mean } \\
\pm \text { SEM) }\end{array}$ & $\begin{array}{l}\text { Sig. ('p' } \\
\text { Value) }\end{array}$ \\
\hline$A C$ & $\begin{array}{l}1.04 \pm \\
0.03\end{array}$ & $\begin{array}{l}1.02 \pm \\
0.04\end{array}$ & $\begin{array}{l}0.97 \pm \\
0.04\end{array}$ & 0.44 \\
\hline$B D$ & $\begin{array}{l}1.00 \pm \\
0.03\end{array}$ & $\begin{array}{l}1.02 \pm \\
0.04\end{array}$ & $\begin{array}{l}0.98 \pm \\
0.03\end{array}$ & 0.39 \\
\hline$A B$ & $\begin{array}{l}2.54 \pm \\
0.05\end{array}$ & $\begin{array}{l}2.55 \pm \\
0.05\end{array}$ & $\begin{array}{l}2.45 \pm \\
0.05\end{array}$ & 0.35 \\
\hline$V D$ & $\begin{array}{l}0.49 \pm \\
0.01 \\
\end{array}$ & $\begin{array}{l}0.46 \pm \\
0.02 \\
\end{array}$ & $\begin{array}{l}0.49 \pm \\
0.02\end{array}$ & 0.63 \\
\hline$W Y$ & $\begin{array}{l}1.66 \pm \\
0.05\end{array}$ & $\begin{array}{l}1.78 \pm \\
0.06\end{array}$ & $\begin{array}{l}1.59 \pm \\
0.06\end{array}$ & 0.15 \\
\hline$X Z$ & $\begin{array}{l}5.74 \pm \\
0.09\end{array}$ & $\begin{array}{l}5.68 \pm \\
0.16\end{array}$ & $\begin{array}{l}5.56 \pm \\
0.23\end{array}$ & 0.75 \\
\hline$W X$ & $\begin{array}{l}7.92 \pm \\
0.11 \\
\end{array}$ & $\begin{array}{l}8.01 \pm \\
0.18 \\
\end{array}$ & $\begin{array}{l}7.93 \pm \\
0.13 \\
\end{array}$ & 0.89 \\
\hline$H D$ & $0.51 \pm .02$ & $\begin{array}{l}0.55 \pm \\
0.02\end{array}$ & $\begin{array}{l}0.54 \pm \\
0.02\end{array}$ & 0.52 \\
\hline
\end{tabular}


In this study, the height of mandibular body and the distance between the alveolar crest and mental foramen were found to decrease with age. This is attributed to resorption in the mandibular part above the mental foramen due to loss of teeth and periodontal diseases. Local factors such as masticatory forces would also contribute to this reduction in the mandibular bone ${ }^{46}$.

The position of mental foramen, especially its vertical relations within the body of the mandible varies from infancy to old age. The mental foramen is located midway between the upper and lower border of the mandible in the presence of the teeth, and appears to be near the upper margin of mandible in edentulous patient ${ }^{47}$. The distance from the foramen to the inferior border of the mandible remains relatively constant throughout life $\mathrm{l}^{48}$, and the stability of this region does not depend on resorption of alveolar process above the foramen ${ }^{49}$. Anatomically, one mental foramen are found on each side of the mandible. However, in about $2 \%$ to $10 \%$ incidence, the mandible was reported to possess more than one foramen ${ }^{50}$, and up to $0.06 \%$ incidence showed absence of mental foramen ${ }^{35}$. Nevertheless, there was no mention about the pathway of mental nerves and vessels in the absence of the mental foramen in the literature. In brief, the varied number and locations of mental foramen are essential for identification of unknown skeletal remains in forensic scenarios.

In the present study, the morphometric measurements of mandibular bone were studied among the different races i.e. Malays, Chinese and Indians. We speculate that different ethnic races might be consuming different type of food. Even, the food is different in each of the races. For instance, in Indians, they consume food such as legumes, grains and nuts, which are hard in consistency that will require active mastication. However, in Chinese, food such as noodles, rice and soup were consumed, which were soft food with smoother consistency. In the Malays, the type of food taken was a mixture between Indians and Chinese. From the results, there was no significant difference in mental foramen measurements between the three racial groups, which could be attributed to the interplay between cultures and intermarriage between the groups, leading to insignificant changes among them.

\section{Conclusion}

In conclusion, the mental foramen may exist in different morphological shapes, position and measurements. These factors may be influenced by various social-demographic factors, which may contribute to its final appearance. The result of the present study would enhance human identification by analysis of mental foramen. Further research may be needed to expand on other related variables in a larger sample size for validation and comparison purposes.

\section{Acknowledgement}

The authors would like to extend their sincere appreciation and gratitude to Universiti Kebangsaan Malaysia for the financial support (Grant-UKM FPR.4/244/FF-2016-235) and the Department of Forensic Medicine, Hospital Kuala Lumpur for provision of the data.

\section{References}

1. Nidhin, N, Prashanth, S, Laxmikanth C, Veena, KM, Prasanna, KR, Prathima, S. Gender determination using the mental foramen. Journal Cranio-Maxillary Diseases. 2015; 4(2): 144-147.

2. Hu KS, Koh KS, Han SH, Shin KJ, Kim HJ. Sex determination using nonmetric characteristics of the mandible in Koreans. J Forensic Sci. 2006; 51: 1376-82.

3. Haghanifar S, Rokouei M. Radiographic evaluation of mental foramen in a selected Iranian population. Indian J Dent Res. 2009; 20: 150-2.

4. Moiseiwitsch JR. Position of the mental foramen in a North American, white population. Oral Surg Oral Med Oral Pathol Oral Radiol Endod. 1998; 85: 457-60.

5. Haghanifar S, Rokouei M. Radiographic evaluation of the mental foramen in a selected Iranian population. Indian J Dent Res. 2009; 20: 150-2.

6. Green RM. The position of the mental foramen: a comparison between the southern (Hong Kong) Chinese and other ethnic and racial groups. Oral Surg Oral Med Oral Pathol. 1987; 63: 287-90.

7. Ngeow WC, Yuzawati Y. The location of the mental foramen in a selected Malay population. J Oral Sci. 2003; 45:171-5.

8. Neo J. Position of the mental foramen in Singaporean Malays and Indians. Anesth Prog. 1989; 36: 276-8.

9. Mwaniki DL, Hassanali J. The position of mandibular and mental foramina in Kenyan African mandibles. East Afr Med J. 1992; 69: 210-3.

10. Al Jasser NM, Nwoku AL. Radiographic study of the mental foramen in a selected Saudi population. Dentomaxillofac Radiol. 1998; 27: 341-3.

11. Sankar DK, Bhanu SP, Susan PJ. Morphometrical and morphological study of mental foramen in dry dentulous mandibles of South Andhra population of India. Indian J Dent Res. 2011; 22: 542-6. 
12. Olasoji HO, Tahir A, Ekanem AU, Abubakar AA. Radiographic and anatomic locations of mental foramen in northern Nigerian adults. Niger Postgrad Med J. 2004; 11: 230-3.

13. Koppe T. Summary of: A comparative anthropometric study of the position of the mental foramen in three populations. Br Dent J. 2012; 212:188-9.

14. Mbajiorgu EF, Mawera G, Asala SA, Zivanovic S. Position of the mental foramen in adult black Zimbabwean mandibles: a clinical anatomical study. Cent Afr J Med. 1998; 44: 24-30.

15. Medha BS, Krishna BR, Kirty N. Evaluation of the Position of Mental Foramen and Its Correlation with Age in Selected Indian Population, Using Digital Panoramic Radiograph. Int J Dental Sci Res. 2015; 3(4): 87 $-91$.

16. Poswillo DE. Mandible. In: Sperber GH, Sperber SM, Guttmann GD, editors. $2^{\text {nd }}$ ed. Craniofacial embryogenetics and development. USA: People's medical publishing house. 2010: 149160.

17. Dudar JC, Pfeiffer S, Saunders SR. Evaluation of morphological and histological adult skeletal age-at-death estimation techniques using ribs. J Forensic Sci. 1993; 38(3): 677-685.

18. Maat GJ, Maes A, Aarents MJ, Nagelkerke NJ. Histological age prediction from the femur in a contemporary Dutch sample. The decrease of nonremodeled bone in the anterior cortex. $\mathrm{J}$ Forensic Sci. 2006; 51(2): 230-237.

19. Bou Serhal C, Jacobs R, Flygare L, Quirynen M, Van Steenberghe D. Perioperative validation of localisation of the mental foramen.

Dentomaxillofac Radiol. 2002; 31(1): 39-43.

20. Cavalcanti MG, Yang J, Ruprecht A, Vannier MW. Validation of spiral computed tomography for dental implants. Dentomaxillofac Radiol. 1998; 27(6): 329-33.

21. Chau A. Comparison between the use of magnetic resonance imaging and conebeam computed tomography for mandibular nerve identification. Clin Oral Implants Res. 2012; 23 (2): 253-56.

22. Kqiku L, Sivic E, Weiglein A, Städtler P. Position of the mental foramen: an anatomical study. Wien Med Wochenschr. 2011; 161(9-10): 27273.

23. Liang X, Jacobs R, Hassan B, Li L, Pauwels R, Corpas L. A comparative evaluation of Cone Beam Computed Tomography (CBCT) and MultiSlice CT (MSCT) Part I. On subjective image quality. Eur J Radiol. 2010; 75(2): 265-69.

24. Ngeow WC, Yuzawati Y. The location of the mental foramen in a selected Malay population. J Oral Sci. 2003; 45(3): 171-5.

25. Tebo HG, Telford IB. An analysis of the variations in position of the mental foramen. Anat Rec. 1950; 107: 61-66.

26. Saito K, Soares de Araújo N, Saito MT, João de Jesus VP, Luiz de CP. Analysis of the mental foramen using cone beam computerized tomography. Rev. odontol. 2015; 44(4).

27. Shailaza, S, Sudha J. Mental foramen: a morphological and morphometrical study Rahul Rai International J Healthcare Biomed Res 2014; 2(4): 144-150.

28. IBM Corp. Released 2013. IBM SPSS Statistics for Windows, Version 22.0. Armonk, NY: IBM Corp.

29. Singh IJ, Gunberg DL. Estimation of age at death in human males from quantitative histology of bone fragments. Am J Phys Anthropol. 1970; 33(3): 373-381.

30. Sharpe WD. Age changes in human bone: an overview, Bull N Y Acad Med. 1979; 55(8): 757773.

31. Standring S. Gray's anatomy: the anatomical basis of clinical practice, $39^{\text {th }}$ ed. British Library Cataloguing in Publishing Data. 2005: 87 -88 .

32. Kerley ER. The microscopic determination of age in human bone, Am J Phys Anthropol. 1965; 23(2): 149-163.

33. Habib-ur-Rehman, Haider SM. Panoramic radiographic study of mental foramen in a selected Pakistani population. Int J Oral Maxillofac Surg. 2007; 36(11): 1033-1033.

34. Neo J. The Position of the mental foramen in Singaporean Malays and Indians. Anesth Prog. 1989; 36: 276-278.

35. Bergman RA, Afifi AK, Miyauchi R. Absence and Variations on Mental Foramina. Anatomy Atlases. An Anatomy Digital Library. Illustrated Encyclopedia of Human Anatomic Variation: Opus V: Skeletal Systems. http: / / www.anatomyatlases.org/ (Last assessed: 14.11.2016)

36. Green RM. The position of the mental foramen: A comparison between the southern (Hong Kong) Chinese and other ethnic and racial groups. Oral Surg Oral Med Oral Pathol. 1987; 63: 287-290.

37. YeÕilyurt, H, Aydlnllo, A, Kavakll, A. Ekinci, N.Ero, C. Haclaliullar, M. Local differences in the position of the mental foramen. Folia Morphol. 2008; 67(1): 32-35.

38. Boonpiruk N. Location of mental foramen in Thai skulls. J Dent Assoc Thai. 1975; 25: 295302. 
39. Santini A, Land MA. A comparison of the position of the mental foramen in Chinese and British mandibles. Acta Anat. 1990; 137: 208212.

40. Tebo HG, Telford IB. An analysis of the variations in position of the mental foramen. Anat Rec. 1950; 107: 61-66.

41. Wang TM, Shih C, Liu JC, Kuo KJ. A clinical and anatomical study of the location of the mental foramen in adult Chinese mandibles. Acta Anat. 1986; 126: 29-33.

42. Zivanovic S. Some morphological characteristics of the East African mandible. Acta Anat. 1970; 77: 109-119.

43. Cagri U, Cihan B, Ismail S, Ali MA, Yusuf Z. Bone height measurement of maxillary and mandibular bones in panoramic radiographs of edentulous patients. J Clinc. Exp Dent. 2011; 3 (1): 5-9.

44. Ortman LF, Hausmann E, Dunford RG. Skeletal osteopenia and residual ridge resorption.J Prosthet Dent. 1989; 61: 321-5.

45. De Baat C, Kalk W, Vant Hof M. Factors connected with alveolar bone resorption among instutionalised elderly people. Community Dent Oral Epidemiol. 1993; 21: 317-20.

46. Enlow DH, Bianco HJ, Eklund S. The remodeling of the edentulous mandible, J Prosthet Dent. 1976; 36(6): 685-693.

47. Poswillo DE. Mandible. In: Sperber GH, Sperber $S M$, Guttmann GD, editors. $2^{\text {nd }}$ ed. Craniofacial embryogenetics and development. USA: People's medical publishing house. 2010: 149160

48. Wical KE, Swoope CC. Studies of residual ridge resorption. Part 1. Use of panoramic radiographs for evaluation and classification of mandibular resorption. J Prosthet Dent. 1974; 32: 7-12.1

49. Lindh C, Peterson A, Klinge B. Measurements of distance related to the mandibular canal in radiographs. Clin Oral Implant Res. 1995; 6: 96103.

50. Punjabi SK, Habib UR, Ahmed S, Haider M. Radiographic Position of Mental Foramen in Selected Pakistani Population. J Pak Dent Assoc. 2010; 19(2): 105-109. 